九州大学学術情報リポジトリ

Kyushu University Institutional Repository

\title{
Comparison of Photosynthetic Response of Two Soybean Cultivars to Soil Flooding
}

Cho, Jin-Woong

Collage of Agriculture and Life Science, Chungnam National University

$\mathrm{Ji}$, Hee Chung

Collage of Agriculture and Life Science, Chungnam National University

Yamakawa, Takeo

Faculty of Agriculture, Kyushu University

https://doi.org/10.5109/9233

出版情報: 九州大学大学院農学研究院紀要. 51 (2)，pp.227-232，2006-10-27. Faculty of Agriculture, Kyushu University

バージョン：

権利関係 : 


\title{
Comparison of Photosynthetic Response of Two Soybean Cultivars to Soil Flooding
}

\author{
Jin-Woong $\mathrm{CHO}^{1}$, Hee Chung $\mathrm{JI}^{1}$ and Takeo YAMAKAWA ${ }^{*}$ \\ Laboratory of Plant Nutrition, Division of Soil Science and Plant Production, \\ Department of Plant Resources, Faculty of Agriculture, Kyushu University, \\ 6-10-1 Hakozaki, Fukuoka 812-8581, Japan. \\ (Received June 5, 2006 and accepted July 24, 2006)
}

\begin{abstract}
This experiment was conducted to compare the tolerant responses between two soybean cultivars Sowonkong (tolerant) and Hannamkong (sensitive) when these were subjected to flooding stress. Plants were grown under photoperiod of natural light with day temperature of $30.6 \pm 5.3^{\circ} \mathrm{C}$ and night temperature of $22.2 \pm 1.7^{\circ} \mathrm{C}$. Flooding, filled with tap water to $1 \mathrm{~cm}$ above the level of the soil surface, was experimented for nine days when plants were at the vegetative (V4 to V5) and reproductive (R2; flowering) stage. The photosynthesis and transpiration of soybean with flooding declined progressively in comparison with the non-flooding at V4 to V5 and R2 stage. The Fv/Fm ratio and chlorophyll content also showed a constant decrease by the progressive flood stress. The photosynthesis, transpiration, Fv/Fm ratio and chlorophyll content were more affected by the flooding in Hannamkong than in Sowonkong. The $\mathrm{NH}_{4}$ content increased up to five days after flooding but thereafter, rapidly decreased at both stages except for Sowonkong flooded at V4 to V5 stage. The $\mathrm{NO}_{3}$ content was not greatly changed in soybean leaf but there was a great reduction of $\mathrm{NO}_{3}$ in root by the flood stress. The growth characteristics of flooded plants also were reduced compared to the non-flooded plant at both stages. The seed yield, pod number and seed weight significantly reduced when the flood stress was applied at V4 to V5 and R2 stage. Specially, the yield reduction was more sensitive at R2 than V4 toV5 stage in Hannamkong. Furthermore, in this paper, the relationship between photosynthetic parameters and yield will be discussed.
\end{abstract}

\section{INTRODUCTION}

The damage on plant by various stresses during a growing season showed diversity in each growth stage. In general, the disaster occurred vigorously at seedling, germination, early vegetative growth and reproductive growth stage. Damages affected by the flooding on plants are usually attributed to an insufficient oxygen supply to maintain root respiration. Excessive water stress may be detrimental to the root growth, and the nodule formation and function in soybean (Russel, 1990; Sallam and Scott, 1987). Also, flood duration effects on soybean manifested the yellowing and abscission of leaves at the lower nodes, stunting, and reduced the dry weight and seed yield (Scott et al., 1989). Soybean flooded at vegetative stage reduced leaf area, dry weight, and plant weight (Choi et al., 1995; Griffin and Saxton, 1988; Linkemer et al., 1998; Scott et al., 1989). Specially, Griffin and Saxton (1988) stated that soybean flooded at V6 had severe chlorosis and stunt after four days standing water and also, these researchers reported that crop growth rate had been usually affected by the flooding stress which was applied for more than two days.

On the other hand, excessive water content of soil leads to depletion of soil oxygen and anaerobic conditions. When plants were hypoxic or anoxic, the oxygen dependent pathway was suppressed, the functional relationship between roots and shoots was disturbed, and carbon assimilation was also inhibited (Vartapetian

${ }^{1}$ Department of Crop Science, Collage of Agriculture and Life Science, Chungnam National University, Daejeon, 305-764, South Korea

* Corresponding author (E-mail: yamakawa@agr.kyushu-u.ac.jp) and Jackson, 1997). Waterlogging also had been found to be harmful to plants by a rapid reduction of photosynthetic rate and stomatal conductance, and the reduction of photosynthesis in mungbean might be due to a mechanism independent from stomatal closure (Ahmed et al., 2002). Since many researchers reported on $\mathrm{CO}_{2}$ assimilation, it had been attributed to direct effect of flooding on photosynthetic reactors (Yordanova and Popova, 2001), reduced the activity of some photosynthetic enzymes, and inhibited photosynthetic electron transport and photosystem II activity (Ladygin, 1999). However, details on the mechanisms by which flooding affects soybean $\mathrm{CO}_{2}$ assimilation were not well known.

The aims of this study are to investigate on change of photosynthesis and their factors in soybean under excessive water stress by using a potable photosynthetic apparatus.

\section{MATERIALS AND METHODS}

\section{Plant growth condition}

The soybean culture carried out on plastic pots $(40 \mathrm{~cm} \times 25 \mathrm{~cm} \times 3.0 \mathrm{~m})$ filled up with silt loam soil in greenhouse affiliated to Chungnam National University, Daejeon, Korea using two soybean (Glysine max L. Merr.) cultivars, Sowonkong and Hannamkong. Sowonkong was recognized as a tolerant cultivar of excessive water stress but Hannamkong was known as a sensitive cultivar of excessive water stress (Cho and Yamakawa, 2006). Seeds were sowed with three plants of two hills. N, P and K were applied at 3,3 and $4 \mathrm{~kg} / 10 \mathrm{a}$ and incorporated into soil before sowing. Plants were grown under photoperiod of natural light with day temperature of $30.6 \pm 5.3^{\circ} \mathrm{C}$ and night temperature of $22.2 \pm 1.7^{\circ} \mathrm{C}$. The flood stress as filled with tap water up 
to $1 \mathrm{~cm}$ above the soil surface level was done during nine days when plants were at the vegetative (V4 to V5) and reproductive (R2; flowering stage) stage (Fehr and Caviness, 1977). Control plants remained well watered soil (about 60\% soil moisture) during the experiment.

\section{Measurements of Photosynthetic rate and chloro- phyll content}

The photosynthetic rate and transpiration rate were measured using a potable photosynthetic apparatus (LCA-4, ADC, Halma group company, UK). The light intensity was measured at $1,300 \mu \mathrm{mol} \mathrm{m}^{-2} \mathrm{~s}^{-1} \mathrm{PAR}$ (photosynthetically active radiation). The $\mathrm{CO}_{2}$ concentration was 330 to $370 \mathrm{ppm}$ and the flow rate of the air was

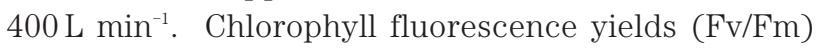
was measured using a potable chlorophyll flurometer (FIM 1500, ADC, Halma group company, UK). The measurements were obtained at the same leaf used for the gas exchange determination after a dark adaptation time for $30 \mathrm{~min}$. Chlorophyll content was measured by IRRI method (Yoshida et al., 1972) using a spectrophotometer (Spectronic genesys 2PC, USA) at $652 \mathrm{~nm}$. These data were obtained from six plants at each treatment on $3,5,7$ and 9 days after the starting of the flood stress. The photosynthetic rate, transpiration rate and $\mathrm{Fv} / \mathrm{Fm}$ were measured on fully expanded 4th trifoliate leaflets between 10:00 and 14:00 h at the temperature range of 28 to $34^{\circ} \mathrm{C}$.

\section{Analysis of nitrate and ammonium contents}

Nitrate content was determined by using modified Cataldo et al. (1975) method. For the nitrate analysis, the fresh harvested samples were grounded with a mortar and pestle in 2 volumes of deionized water and centrifuged for 15 minutes. The supernatant was used for analysis. Extracted solution of $0.2 \mathrm{~mL}$ was mixed with $0.8 \mathrm{~mL}$ of $5 \%$ salicylic acid in sulfuric acid. After 20 minutes, this complex solution was gently mixed with $19.0 \mathrm{ml}$ of $2 \mathrm{M} \mathrm{NaOH}$ (over $\mathrm{pH} 12$ ). Absorbance was read at $410 \mathrm{~nm}$ (Spectronic genesys 2PC, USA). For ammonium analysis, $0.2 \mathrm{~mL}$ of extracted solution was added by $1 \mathrm{~mL}$ of reagent I ( $1 \mathrm{~L}$ of deionized water containing $50 \mathrm{~g}$ phenol and $0.25 \mathrm{~g}$ sodium nitroprusside) and $1 \mathrm{~mL}$ of reagent II ( $1 \mathrm{~L}$ of deionized water containing $25.0 \mathrm{~g}$ sodium hydroxide and $21.0 \mathrm{~g}$ sodium hypochlorite). This mixture was incubated in water bath at 50 to $60^{\circ} \mathrm{C}$ for 5 minutes. After diluting solution with $23 \mathrm{~mL}$ water, the absorbance of the sample was read at $625 \mathrm{~nm}$.

\section{RESULTS}

\section{Photosynthetic rate}

The photosynthetic rate of two soybean cultivars during flooding periods declined progressively as compared with the non-flooding plant at both growth stages (Fig. 1; a and b). The reduction of photosynthetic rate between two cultivars was more obvious and occured much earlier in Hannamkong (sensitive) than Sowonkong (tolerant) by flooding. The reduction of photosynthetic rate with flooding showed 55\% and 63\%
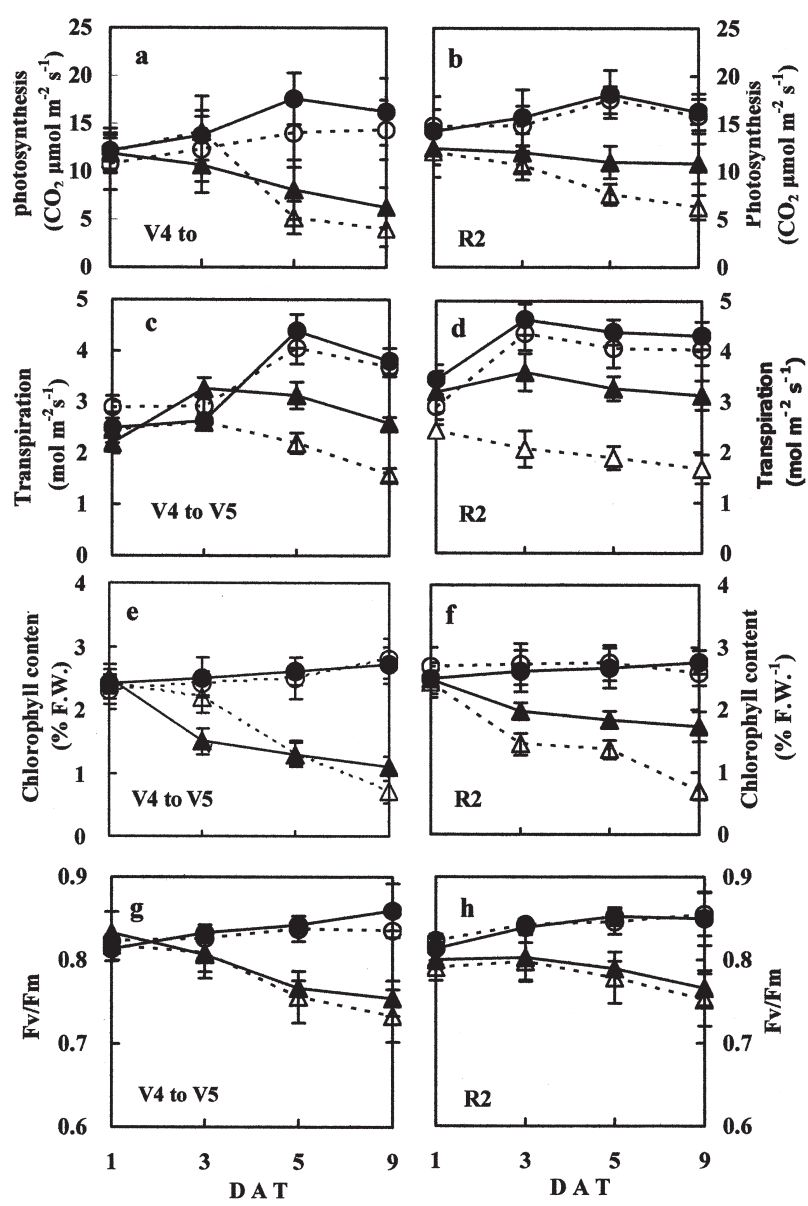

Fig. 1. Photosynthesis, transpiration, chlorophyll content, and $\mathrm{Fv} / \mathrm{Fm}$ ratio in two soybean cultivars over nine days of the flood treatment at V4 to V5 and R2 stage.

Solid lines and closed symbol show Sowonkong and dashed lines and open symbol show Hannamkong. $\bigcirc$ and $\bigcirc$ show control, and $\boldsymbol{\Delta}$ and $\triangle$ show flooded plants. Means are shown $\pm \mathrm{SE}(\mathrm{n}=6$ plants $)$.

at 5 days in Hannamkong and Sowonkong at V4 to V5 stage, repectively and showed $39 \%$ and $58 \%$ in Hannamkong and Sowonkong at R2 stage, respectively. Therefore, the effect of flooding stress on photosynthetic rate at both growth stages showed similar tendency in each other. The transpiration rate showed almost similar trend as the photosynthetic rate (Fig. 1; c and d). A sharp reduction was observed at three days after the flooding stress initiation. Transpiration rate on nine days after flooding decreased approximate $32 \%$ and $28 \%$ compared to that of non-flooding at V4 to V5 and R2 stage in Sowonkong, respectively and decreased 56\% and 58\% compared to that of non-flooding at V4 to V5 and R2 stage in Hannamkong, respectively.

The flooded soybeans showed a constant decrease of chlorophyll content and the chlorophyll content was clearly reduced at longer flooding status on both growth stages (Fig. 1; e and f). The chlorophyll content was decreased from one day after the flooding. The reduction of the chlorophyll content was more in Hannamkong than Sowonkong. However, there was a similar trend of the chlorophyll content on both V4 to V5 and R2 stage in flooded soybeans. 
The Fv/Fm ratio is a parameter that allows the detection of any stresses to the photosystem II and the possible existence of photoinhibition. In this experiment, flooded soybeans clearly showed a constant decrease of the Fv/Fm from one day and attaining lowest value of the Fv/Fm ratio on nine days (Fig. 1; g and $h$ ). The Fv/Fm ratio with flooding was lower in Hannamkong than Sowonkong at both growth stages.

\section{$\mathrm{NH}_{4}$ and $\mathrm{NO}_{3}$ contents}

The $\mathrm{NH}_{4}$ content of leaf and root in two soybean cultivars with progressive flooding stress was shown in Fig. 2. The $\mathrm{NH}_{4}$ content of soybean leave with the flooding stress was tended to increase up to five days after treatment but thereafter, it showed rapid reducing trend at both growth stages except for Hananmkong at V4 to V5 stage (Fig. 2). However, there was no great change on the $\mathrm{NH}_{4}$ content of root up to five days after flooding but there was a little decrease at more than five days.

The $\mathrm{NO}_{3}$ content in soybean leave showed no greatly
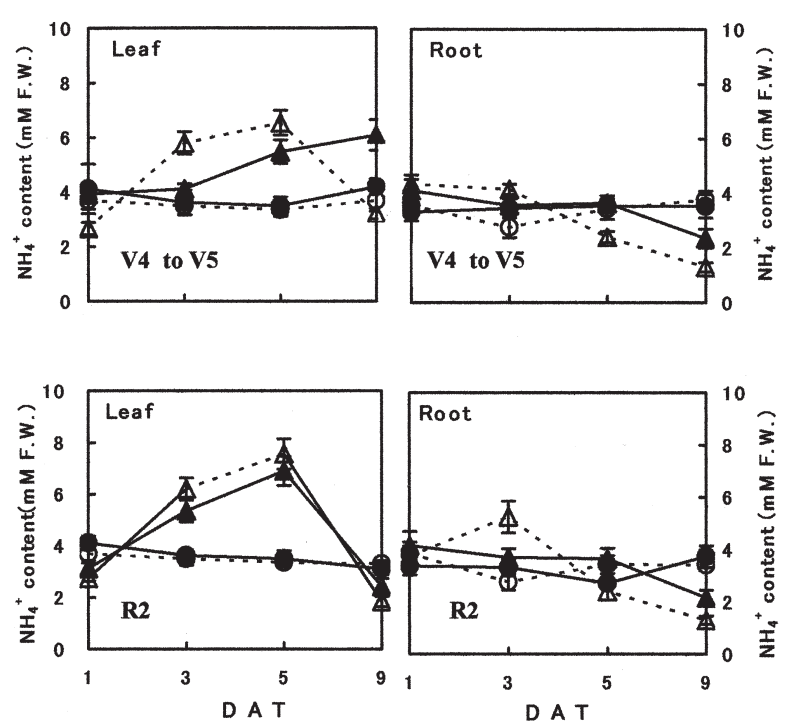

Fig. 2. $\mathrm{NH}_{4}{ }^{+}$content in two soybean cultivars over nine days of the flood treatment at V4 to V5 and R2 stage. Solid lines and closed symbol show Sowonkong and dashed lines and open symbol show Hannamkong. and $\bigcirc$ show control, and $\boldsymbol{\Delta}$ and $\triangle$ show flooded plants. Means are shown $\pm \mathrm{SE}(\mathrm{n}=5$ plants $)$. change up to five days when soybeans were subjected to flood stress but showed the reduction of $\mathrm{NO}_{3}$ content from five days after beginning of the flooding at both growth stages (Fig. 3). Also, the $\mathrm{NO}_{3}$ content in the flood stressed soybean root declined constantly compared to the non-flooding soybean root at both growth stages (Fig. 3). The $\mathrm{NO}_{3}$ content of leaf and root was more severely reduction in Hannamkong than Sowonkong.

\section{Growth and yield}

The growth characteristics of two soybeans up to nine days after beginning the flood stress at V4 to V5 and R2 stage were shown in Table 1 . When the soybeans were subjected to flooding, the plant height reduced compared to the non-treated plants at both growth stages. The number of leaf per plant on flooded soybeans also was decreased by $9 \%$ and 15\% compared to that of non-flood at V4 to V5 and R2 stage in Sowonkong, respectively and decreased by 54\% and
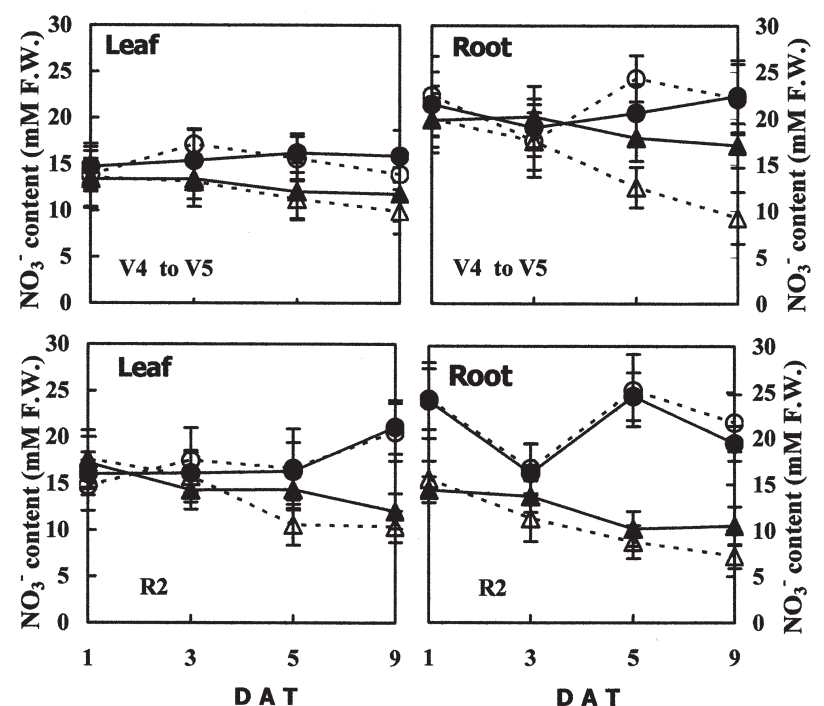

Fig. 3. $\mathrm{NO}_{3}{ }^{-}$content in two soybean cultivars over nine days of the flood treatment at V4 to V5 and R2 stage.

Solid lines and closed symbol show Sowonkong and dashed lines and open symbol show Hannamkong. $\mathrm{and} \bigcirc$ show control, and $\boldsymbol{\Delta}$ and $\triangle$ show flooded plants. Means are shown $\pm \mathrm{SE}(\mathrm{n}=5$ plants $)$.

Table 1. Growth characteristics in two soybean cultivars over nine days of the flood stress

\begin{tabular}{|c|c|c|c|c|c|c|c|c|}
\hline \multirow{2}{*}{ Cultivars } & \multirow{2}{*}{$\begin{array}{l}\text { Treated } \\
\text { stage } \dagger\end{array}$} & \multirow{2}{*}{ Treatment } & \multirow{2}{*}{$\begin{array}{l}\text { Plant } \\
\text { height } \\
(\mathrm{cm})\end{array}$} & \multirow{2}{*}{$\begin{array}{l}\text { Leaf no. } \\
\left(\text { plant }^{-1}\right)\end{array}$} & \multirow{2}{*}{$\begin{array}{c}\text { Leaf area } \\
\left(\mathrm{cm}^{2} \text { plant }^{-1}\right)\end{array}$} & \multicolumn{3}{|c|}{ Dry weight (g plant ${ }^{-1}$ ) } \\
\hline & & & & & & Leaf & Stem & Root \\
\hline \multirow[t]{4}{*}{ Sowonkong } & V4 to V5 & Non-flood & $49.5 \pm 3.5^{*}$ & $26.7 \pm 3.3$ & $355 \pm 33$ & $1.17 \pm 0.16$ & $0.90 \pm 0.11$ & $0.26 \pm 0.02$ \\
\hline & & Flood & $44.2 \pm 3.1$ & $24.3 \pm 4.1$ & $347 \pm 29$ & $1.07 \pm 0.21$ & $0.58 \pm 0.05$ & $0.27 \pm 0.05$ \\
\hline & $\mathrm{R} 2$ & Non-flood & $58.1 \pm 2.9$ & $63.5 \pm 2.9$ & $747 \pm 43$ & $2.40 \pm 0.25$ & $1.78 \pm 0.18$ & $2.38 \pm 0.13$ \\
\hline & & Flood & $54.9 \pm 4.1$ & $53.8 \pm 2.4$ & $749 \pm 19$ & $2.36 \pm 0.16$ & $1.98 \pm 0.20$ & $1.94 \pm 0.12$ \\
\hline \multirow[t]{4}{*}{ Hannamkong } & V4 to V5 & Non-flood & $53.3 \pm 3.3$ & $28.7 \pm 2.7$ & $379 \pm 41$ & $1.75 \pm 0.21$ & $0.90 \pm 0.11$ & $0.27 \pm 0.02$ \\
\hline & & Flood & $44.2 \pm 4.7$ & $13.3 \pm 1.8$ & $197 \pm 26$ & $0.83 \pm 0.05$ & $0.60 \pm 0.05$ & $0.15 \pm 0.01$ \\
\hline & $\mathrm{R} 2$ & Non-flood & $56.8 \pm 3.9$ & $65.7 \pm 3.5$ & $985 \pm 33$ & $4.80 \pm 0.39$ & $3.16 \pm 0.25$ & $3.43 \pm 0.23$ \\
\hline & & Flood & $51.4 \pm 2.1$ & $54.8 \pm 2.1$ & $794 \pm 39$ & $3.15 \pm 0.20$ & $2.36 \pm 0.14$ & $2.60 \pm 0.12$ \\
\hline
\end{tabular}

†According to Fehr and Caviness (1977). *Mean \pm SE (n=9 plants). 
Table 2. Yield on different soybean stages with the flood stress during 10 days

\begin{tabular}{|c|c|c|c|c|}
\hline Cultivars & Treatment & $\begin{array}{l}\text { Pod no. } \\
\left(\text { plant }^{-1}\right)\end{array}$ & $\begin{array}{c}\text { Yield } \\
\left(\text { g plant }^{-1}\right)\end{array}$ & $\begin{array}{c}100 \text { seed } \\
\text { weight (g) }\end{array}$ \\
\hline \multirow[t]{3}{*}{ Sowonkong } & Non-flood & $45.2 \pm 8.8^{*}$ & $10.9 \pm 2.1$ & $11.9 \pm 0.9$ \\
\hline & Flood V4 to V5† & $32.5 \pm 6.7$ & $7.6 \pm 1.7$ & $10.1 \pm 0.6$ \\
\hline & $\mathrm{R} 2 \dagger$ & $29.8 \pm 2.7$ & $6.7 \pm 0.5$ & $9.9 \pm 0.6$ \\
\hline \multirow[t]{3}{*}{ Hannamkong } & Non-flood & $44.0 \pm 3.1$ & $11.3 \pm 1.2$ & $12.1 \pm 0.8$ \\
\hline & Flood V4 to V5 & $34.7 \pm 7.2$ & $7.9 \pm 1.0$ & $11.1 \pm 0.5$ \\
\hline & $\mathrm{R} 2$ & $27.7 \pm 6.1$ & $4.5 \pm 0.5$ & $8.5 \pm 0.4$ \\
\hline
\end{tabular}

$\dagger$ According to Fehr and Caviness (1977). *Mean \pm SE ( $n=9$ plants).

17\% compared to that of non-flood at V4 to V5 and R2 stage in Hannamkong, respectively. The leaf area showed similar trend as the leaf number per plant. The dry weight also reduced by the flood stress. The reduced dry weight was more in Hannamkong than Sowonkong. Leaf growth with the flood stress was the most sensitive plant part and reduced by 53\% and 34\% compared to that of non-flood at V4 to V5 and R2 stage, respectively, and the growth reduction of root and stem in Hannamkong was $33 \%$ and $44 \%$ at V4 to V5 stage, and $25 \%$ and $24 \%$ at $\mathrm{R} 2$ stage, respectively.

The yield, pod number and 100 seed weight with the flood stress for nine days at V4 to V5 and R2 stage was shown in Table 2. The pod number per plant showed significant reduction when plants were subjected to flooding at V4 to V5 and R2 stage and showed no difference between two soybean cultivars at both growth stages. The effect of flood stress on the yield per plant showed the reduction when the flooding for nine days was applied at V4 to V5 and R2 stage. Especially, the yield reduction was more sensitive at R2 stage than V4 to V5 stage in Hannamkong. The 100 seed weight also significantly decreased when the flood stress was applied at R2 stage.

\section{DISCUSSION}

The damage on soybean plant by various stresses during a growing season showed diversity in each growth stage. In general, the disaster occurred vigorously at seedling, germination, early vegetative growth, reproductive growth stage, and the flood stress has been known to be a major limiting factor for soybean growth and yield during the rainy season, and, hence, the reaction against the flood stress at early vegetative growth stage and flowering stage is very important. Soybean is sensitive crop to the flooding and generally it was influenced by the flood stress on growth and yield during V4 to R5 growth stage (Choi et al., 1995; Cho and Yamakawa, 2006; Griffin and Saxton, 1988; Linkemer et al., 1998; Scott et al., 1989). Thus, the flood stress affects soybean plants through numerous physiological and metabolic processes. The photosynthesis was one of the earliest plant responses to the flood stress which reduced photosynthetic rate of soybean from one day after beginning of the flooding. This same result was reported by Ahamed et al. (2002). They stated that photosynthesis reduced by $29 \%$ and $25 \%$ within one day of the waterlogging at the vegetative and reproductive stages in mungbean, respectively. Yordanova and Popova (2001) also stated that the soil flooding during three or five days led to a noticeable decrease of the $\mathrm{CO}_{2}$ assimilation in barley, and the reduced photosynthesis by the flood stress might be a result of an indirect effect, mediated by stomata closure, causing a reduction in $\mathrm{CO}_{2}$ supply, or effects of flooding on the capacity of plants for $\mathrm{CO}_{2}$ fixation, independent of increased limitation to inward diffusion. The transpiration of soybean decreased from three days after treatment at V4 to V5 stage and decreased from one day at R2 stage when it subjected to the flood stress. Ahamed et al. (2002) reported that transpiration reduction of flooded barley started from two days at vegetative and reproductive stage. Our result, however, decrease of transpiration appeared from three and one days after flooding at V4 to V5 and R2 stage of soybean, respectively. Thus, the constant flood stress reduced the chlorophyll content of two soybean cultivars. The chlorophyll content decreased at three days when the flood stress was applied at both growth stages. On the other hand, the chlorophyll fluorescence measurement showed in Fv/Fm ratio that was a parameter for detection of any damages to the PSII and possible existence of photoinhibition (Long et al., 1994). The flood stress against soybean began to decrease Fv/Fm ratio from one day after flooding at V4 to V5 and R2 stage. When flood stress was subjected to plants, reductions in $\mathrm{CO}_{2}$ assimilation parameters had been reported in variety or cultivar of plants, including citrus (Joseph and Yelenosky, 1991), mungbean (Ahmed et al., 2002), barley (Yordanova and Popova, 2001), and pecan (Smith and Ager, 1988). The photosynthesis and root respiration of citrus trees decreased during 24 days of flood stress. This corroborates the results of Yordanova and Popova (2001) who showed that prolonged flooding to barley caused considerable decline in the photosynthesis, transpiration and chlorophyll content. In a more tolerant species, apple, such changes were not observed. In our results, Sowonkong that was classified as tolerant cultivar showed less reduction than Hannamkong in photosynthesis, transpiration, chlorophyll content and Fv/Fm ratio at the vegetative and the flowering stages (Fig. 1; g and $h)$.

On the other hand, nitrate and ammonium are major sources of inorganic nitrogen taken up by roots of plants. In many crops, the flood stress led to lower con- 
centrations of nitrogen in the shoot, and when plants were subjected to limited nutrient deficits, shoots are more starved than roots. The $\mathrm{NH}_{4}$ content of soybeans leaf under the flooding stress tended to increase up to five days after the treatment but thereafter, it showed rapid reducing trend at both of growth stages except V4 to V5 stage in Hananmkong (Fig. 2). However, there was not great change of the $\mathrm{NH}_{4}$ content of root up to five days after flooding but there was a small decrease at five days or more. Salt- or flood-stressed plants increased the ammonium induced compound (e.g. glutamine, asparagine) but over accumulated $\mathrm{NH}_{4}$ concentration might induce ammonia toxicity that inhibited growth and eventually, these plants would die (Puiatti and Sodek, 1999). Nitrate reduction in plants depended on various factors such as the amount of nitrate supply, species or cultivars, age and carbon assimilation. In this experiment, there was no difference of $\mathrm{NH}_{4}$ content at both V4 to V5 and R2 stage in soybean by the flood stress. Also, Drew and Sisworo (1979) reported that $\mathrm{NO}_{3}$ content were greatly reduced by $2 \mathrm{~d}$ waterlogging stress in shoot of barley. Nutrient deficiency was one aspect of waterlogging injury. In this experiment, the $\mathrm{NO}_{3}$ content in soybean leaf was not greatly changed up to five days when soybeans were subjected to the flood stress but there was a reduction of $\mathrm{NO}_{3}$ content from five days after the beginning to the flooding at both of growth stages (Fig. 3). Also, the $\mathrm{NO}_{3}$ content in stressed soybean root declined constantly as compared to the non-flooding one at both growth stages (Fig. 3). The $\mathrm{NO}_{3}$ content in leaf and root more severely reduced in Hannamkong than Sowonkong.

Many people reported that soybean was more sensitive on the early reproductive stage than on the vegetative stages (Griffin and Saxton, 1988; Scott et al., 1989; Choi et al., 1996; Heatherly and Pringle, 1991; Kwon and Lee, 1988). However, Linkemer et al. (1998) stated that greatest sensitivity to the waterlogging occurred during $7 \mathrm{~d}$ period starting at R3 stage, and the waterlogging reduced yield by $93 \%, 67 \%$ and $30 \%$ at R3, R1 or R5, and V2 stages, respectively. Also, yield loss under waterlogging primarily induced by decreased pod production resulted from fewer pods per reproductive nodes in late planting soybean (Board et al., 1999, Cho and Yamakawa 2006). Board et al. (1999) reported that there was a high significant correlation between yield and pod number and seed size in late-planted soybean. In this experiment, pod number per plant had significant reduction when plants were subjected to flooding at V4 to V5 and R2 stage but showed no difference between two soybean cultivars at both growth stages. Yield had greatly reduction when soybean was subjected to flooding and the yield reduction was more sensitive at R2 stage than V4 to V5 stage in Hannamkong, especially. The 100 seed weight also significantly decreased when flood stress was applied at V4 to V5 and R2 stage.

The reduction in photosynthetic rate of plant subjected to flood stress can be attributed to the closing of stomata, the increasing of ethylene and the declining of Rubisco activity (Yordanova and Popova, 2001). These cumulative effects against flood had been induced to decline crop growth rate (CGR), net assimilation rate (NAR), and leaf expansion rate (LER) of plants (Linkemer et al., 1998). In this experiments, the reduction of photosynthetic rate of soybean against the flood stress induced to decrease CGR and the reduced CGR led to decreased the seed yield.

\section{REFERENCES}

Ahmed, S., E. Nawata, M. Hosokawa, Y. Domae and T. Sakuratani 2002 Alterations in photosynthesis and some antioxidant enzymatic activities of mungbean subjected to waterlogging. Plant Sci., 163: 117-123

Board, J. E., M. S. Kang and B. G. Harvile 1999 Path analysis of the yield formation process for late-planted soybean. Agron. J., 91: 128-135

Cataldo, D. A., M. Haroon, L. E. Schrade and V. L. Youngs 1975 Rapid colorimetric determination of nitrite in plant tissue. Commun. Soil Sci. Plant Ana., 6: 71-80

Choi, K. J., H. S. Lee, S. D. Kim and E. H. Hong 1996 Dry matter and grain yield production of soybean cultivars as affected by excessive water stress at vegetative growth stage and flowering stage. RDA. J. Agri. Sci., 38: 117-122

Choi, K. J., H. S. Lee and Y. W. Kwon 1995 Physiological response of soybean under excessive soil water stress during vegetative growth period. Korean J. Crop Sci, 40: 595-599

Cho, J.-W. and T. Yamakawa 2006 Tolerance differences among small seed soybean cultivars against excessive water stress conditions. J. Fac. Agr. Kyushu Univ., 51: 195-199

Drew, M. C. and E. J. Sisworo 1979 The development of waterlogging damage in young barley plants in relation to plant nutrient status and changes in soil properties. New Physiol., 82: $301-314$

Fehr, W. and C. E. Caviness 1977 Stage of soybean development. Iowa State Univ. Cppo. Ext. Serv. Spec. Rep., 80

Griffin, J. L. and A.M. Saxton 1988 Response of solid-seeded soybean to flood irrigation. II. Flood duration. Agron. J., 80: $885-888$

Heatherly, L. G. and H. C. Pringle 1991 Soybean cultivars response to flood irrigation of clay soil. Agron. J., 88: 231-236

Joseph, C. V. and G. Yelenosky 1991 Photosynthetic response of citrus trees to soil flooding. Physiol. Plant., 81: 7-14

Kwon, Y. W. and M. K. Lee 1988 Physiological responses of soybean plants to flooding at the vegetative growth and the flowering stages. Res. Rept. RDA., 31: 289-300

Ladygin, V. G. 1999 Effect of root zone hypoxia and anoxia on the functional activity and chloroplast ultrastructure in leaves of Pisum sativum and Glycine max. Fiziol. Rast., 46: 246-258

Linkemer, G., J. E. Board and M. E. Musgrave 1998 Waterlogging effects on growth and yield components in late-planted soybean. Crop Sci., 38: 1579-1584

Long, S. P., S. Humphries and G. Falfowski 1994 Photoinhibition of photosynthesis in nature. Annu. Rev. Plant Physiol. Plant Mol. Biol., 45: 622-633

Puiatti, M. and L. Sodek 1999 Waterlogging affects nitrogen transport in the xylem of soybean. Plant Physiol. Biochem., 37: $767-773$

Russell, D. A., D. M. L. Wong and M. M. Sachs 1990 The anaerobic response of soybean. Plant Physiol., 92: 401-494

Sallam, A. and H. D. Scott 1987 Effects of prolonged flooding on soybeans during early vegetative growth. Soil Sci., 144: $61-66$

Scott, H. D., J. DeAngulo, M. B. Daniels and L. S. Wood 1989 Flood duration effects on soybean growth and yield. Agron. J., 81: 631-636

Smith, M. W. and P. L. Ager 1988 Effects of soil flooding on leaf gas exchange of seedling pecan trees. Hor. Sci., 23: 370-372 
Vartapetian, B. B. and M. B. Jackson 1997 Plant adaptation to anaerobic stress. Ann. Bot., 79: 3-20

Yordanova, R. Y. and L. P. Popova 2001 Photosynthetic response of barley plants to soil flooding. Photosynthetica, 39:
$515-520$

Yoshida, D., D. Forno, J. H. Cask and K. A. Gomez 1972

Laboratory manual for physiological of rice. The IRRI. $2^{\text {nd }}$ Edition 